\title{
KAJIAN PROSES RANTAI PASOK PENYEDIAAN RUMAH SUSUN YANG TERJANGKAU OLEH PENGEMBANG BUMN DAN SWASTA DI DKI JAKARTA (STUDI KASUS: SAMESTA SENTRALAND CENGKARENG DAN GREEN PRAMUKA CITY)
}

\author{
Jeckhi Heng ${ }^{1}$, Nurahma Tresani ${ }^{2}$, Nasiruddin Mahmud ${ }^{3}$ \\ ${ }^{1}$ Magister Perencanaan Wilayah dan Kota, Universitas Tarumanagara, Jakarta \\ Surel: jeckhi.heng@gmail.com \\ ${ }^{2}$ Magister Perencanaan Wilayah dan Kota, Universitas Tarumanagara, Jakarta \\ Surel: ntresani@gmail.com \\ ${ }^{3}$ Magister Perencanaan Wilayah dan Kota, Universitas Tarumanagara, Jakarta \\ Surel: nasir.prodeva@gmail.com
}

Masuk: 19-11-2020, revisi: 27-03-2020, diterima untuk diterbitkan: 05-04-2021

\begin{abstract}
Abstrak
Penyediaan hunian yang terjangkau masih menjadi isu besar pada setiap kota-kota besar di Indonesia. Angka urbanisasi yang semakin bertambah tidak membuat penyediaan hunian di kota Jakarta juga ikut bertambah. Penduduk yang ikut program urbanisasi dari Masyarakat Kelas Menengah dan Kelas Masyarakat Berpenghasilan Rendah atau MBR. Penyediaan tanah untuk Rumah Susun yang Terjangkau masih sedikit. Berdasarkan presentasi Direktur Perencanaan Pembiayaan Perumahan Direktorat Jenderal Pembiayaan Perumahan, permasalahan klasik sejak tahun 1992 oleh Pengembangan Kawasan Permukiman PUPR masih berkaitan dengan proses rantai pasok hunian. Pada penelitian ini akan meneliti kembali proses rantai pasok yang sudah dijalankan oleh pengembang-pengembang dan stakeholders yang ada di DKI Jakarta maupun solusi upaya yang akan dilakukan untuk mengatasi hambatan pada penyediaan Rumah Susun yang Terjangkau. Lokasi penelitian berada di Samesta Sentraland Cengkareng dan Green Pramuka City. Pendekatan yang digunakan pada penelitian ini adalah pendekatan kualitatif. Metode analisis yang dilakukan adalah analisis kronologi dan perbandingan pada masing-masing rumah susun yang dikembangkan oleh pengembang. Hasil penelitian menunjukan bahwa penyediaan rumah susun yang terjangkau masih sangat berpengaruh terhadap peraturan yang telah dilakukan oleh pemerintah pada lahan tersebut, serta pemilihan material pada berdirinya rumah susun yang terjangkau masih sangat berpengaruh. Pada kasus Samesta Sentraland Cengkareng, peraturan yang ada pada lokasi proyek mesti menyediakan $20 \%$ dari pengembangan mereka untuk MBR, dan pemilihan material berdasarkan hasil diskusi dengan manager konstruksi. Walaupun perizinan pada kasus Green Pramuka City merupakan rusunami, yang ada hanya anami akibat permintaan calon pembeli untuk menggunakan spesifikasi bahan yang baik.
\end{abstract}

Kata kunci: rumah susun, keterjangkauan, rantai pasok, masyarakat berpenghasilan rendah, pengembang, pemangku kepentingan, pemerintah

\begin{abstract}
The provision of affordable housing is still a big issue in every major city in Indonesia. The increasing number of urbanizations hasn't made the provision of housing in the city of Jakarta also increase. Residents who take part in the urbanization program were from the Middle Class and Low-Income Communities Class. The provision of land for Affordable Flats was still a bit. Based on the presentation of the Director of Housing Financing Planning at the Directorate General of Housing Financing, classic problems have happened since 1992 by the PUPR Settlement Area Development were still related to the housing supply chain process. This research will re-examine the supply chain process that has been carried out by developers and stakeholders in DKI Jakarta as well as solutions to the efforts that will be made to overcome obstacles in the provision of Affordable Flats. The research locations are in Samesta Sentraland Cengkareng and Green Pramuka City. The approach used in this research is a qualitative approach. The analytical method for researching is chronological analysis and comparison of each Affordable Flats where developed by the developer. The results of the study show that the provision of affordable flats is still very influential on the regulations that have been carried out by the government on the land, and the selection of materials for the establishment of Affordable Flats is still very influential. In the case of Samesta Sentraland Cengkareng, the existing regulations at the project site must provide $20 \%$ of their development for MBR, and the selection of materials is based on discussions with the construction manager. Even though the license in the Green Pramuka City case was rusunami, there was only anami due to the request of the prospective buyer to use good material specifications.
\end{abstract}

Keywords: flats, affordability, supply chain, low-income communities, developers, stakeholders, government 
JAKARTA (STUDI KASUS: SAMESTA SENTRALAND CENGKARENG

DAN GREEN PRAMUKA CITY)

\section{PENDAHULUAN \\ Latar Belakang}

Perpindahan penduduk (migrasi) dari desa ke kota di Indonesia dari tahun ke tahun tetap tinggi, akibat bertambahnya lapangan pekerjaan di kota serta mendorong pemerataan ekonomi dengan adanya arus kas yang mengalir dari kaum urban yang bekerja dan menyisihkan pendapatannya untuk keluarga di desa (Hayyu, 2020), khususnya Jakarta. Berdasarkan sampel dari 156 negara, persentase penduduk perkotaan Indonesia yang tinggal di Jakarta sedikit lebih dari 22\%, yang menempatkan Indonesia pada desil kedua dari keunggulan perkotaan secara internasional (Roberts, 2019: 59). Berdasarkan data dari Biro Pusat Statistik DKI Jakarta 2020 tentang tingkat pendidikan masyarakat (BPS DKI, 2020 : 112) dan tingkat pendapatan masyarakat di DKI Jakarta (BPS DKI, 2020 : 123), dijelaskan bahwa sebagian besar penduduk Jakarta adalah Masyarakat Berpenghasilan Rendah (MBR). Hal yang masih menjadi salah satu permasalahan MBR adalah mengenai hunian. Backlog hunian MBR di Jakarta masih menjadi permasalahan dari zaman ke zaman yang tidak dapat diselesaikan.

Definisi Rumah atau Hunian menurut PUPR (2019) adalah bangunan gedung yang berfungsi sebagai tempat tinggal yang layak huni, sarana pembinaan keluarga, cerminan harkat dan martabat penghuninya serta aset bagi pemiliknya, serta sarana pembinaan keluarga (PUPR, 2019: 209). Pengembangan Hunian (Housing Development) adalah kegiatan perencanaan, pembangunan, pemanfaatan, dan pengendalian, termasuk di dalamnya pengembangan kelembagaan, pendanaan dan sistem pembiayaan, serta peran masyarakat yang terkoordinasi dan terpadu (PP No. 14/ 2016). Pengembangan Hunian yang ada di kota besar menjadi tantangan tersendiri seperti halnya penyediaan tanah, sehingga pengembangan hanya bisa berupa rumah susun. Menurut PUPR (2019), Rumah Susun (Flat-Housing) adalah bangunan gedung bertingkat yang dibangun dalam suatu lingkungan yang terbagi dalam bagian-bagian yang distrukturkan secara fungsional dalam arah horizontal maupun vertikal, dan merupakan satuan-satuan yang masing-masing dapat dimiliki dan digunakan secara terpisah, terutama untuk tempat hunian yang dilengkapi dengan bagian bersama, benda bersama, dan tanah bersama (PUPR, 2019: 214).

Dalam upaya berperan sebagai kepanjangan tangan pemerintah dalam mengurangi angka backlog perumahan yang masih tinggi di Indonesia, pengembang perlu memperhatikan supplydemand chain pada pengembangan rumah susun yang terjangkau. Pengembangan hunian MBR dalam bentuk rusunami telah dilakukan oleh Pemerintah Provinsi DKI Jakarta maupun Pemerintah Pusat, tetapi sering sekali realisasinya tidak tepat sasaran. Perumda Pembangunan Sarana Jaya mengatakan DKI Jakarta saat ini tengah mengalami backlog kepemilikan rumah alias kesenjangan antara rumah terbangun dengan yang dibutuhkan rakyat (Triatmojo, 2020). Backlog itu meningkat 10 persen sejak tahun 2015 hingga 2018. Angka ini bahkan diprediksi bertambah seiring pertumbuhan penduduk (Triatmojo, 2020). Sebagai contoh studi kasus di wilayah DKI Jakarta, salah satu rumah susun yang terjangkau dikembangkan oleh pengembang BUMN melalui Perumnas meliputi proyek Samesta Sentraland Cengkareng, sedangkan pengembang swasta seperti PT. Duta Paramindo Sejahtera mengembangkan proyek Apartemen Green Pramuka City. Alasan memilih dua proyek tersebut untuk diteliti karena letak rumah susun yang sangat strategis, dan latar belakang pengembang yang berbeda. Proses rantai pasok yang ada pada dua proyek tersebut menjadi sangat menarik untuk dipelajari, sehingga dapat menemukan hambatan dan kendala rantai pasoknya akan dianalisis untuk menemukan kesimpulan dalam pemecahan solusi persepsi yang sama dalam mengembangkan hunian rusunami MBR, dalam membentuk "National Housing Authorities" yang ada di Indonesia dimana penelitian tersebut perlu dikaji antar tahapan yang saling berhubungan. 


\section{Rumusan Permasalahan}

Penelitian ini secara garis besar akan membahas mengenai rantai pasok dalam penyediaan rumah susun yang terjangkau oleh pengembang di Provinsi DKI Jakarta. Penelitian juga akan memperhatikan penugasan pengembang dan peran stakeholders yang membantu menjalankan rantai pasok, sehingga hambatan dan tantangan dapat diselesaikan sesuai dengan upaya dan solusi yang ada. Adapun pertanyaan penelitian ini adalah:

- Bagaimana proses rantai pasok penyediaan rumah susun yang terjangkau oleh pengembang BUMN dan Swasta?

- Bagaimana perbandingan upaya pengembang BUMN dan Swasta dalam mengatasi hambatan dan tantangan pada proses rantai pasok penyediaan rumah susun yang terjangkau di DKI Jakarta?

\section{Studi Pustaka}

Rantai Pasok Penyediaan Perumahan (Housing supply chain) menurut Hongjuan et al (2019) yang mengutip Christopher (1992) dan Wang et al. (2018) adalah proses transaksi yang mengatur aliran perumahan prefabrikasi, melalui fase hulu dan hilir, memberikan nilai dalam bentuk produk dan layanan kepada pemangku kepentingan atau stakeholders (Hongjuan et al, 2019 : 551). Tahapan housing supply chain menurut Hongjuan et al (2019) terdiri dari konsep, perencanaan dan desain, manufaktur, konstruksi, serta pengoperasian dan pemeliharaan (Hongjuan et al, 2019) seperti yang digambarkan pada gambar berikut ini:

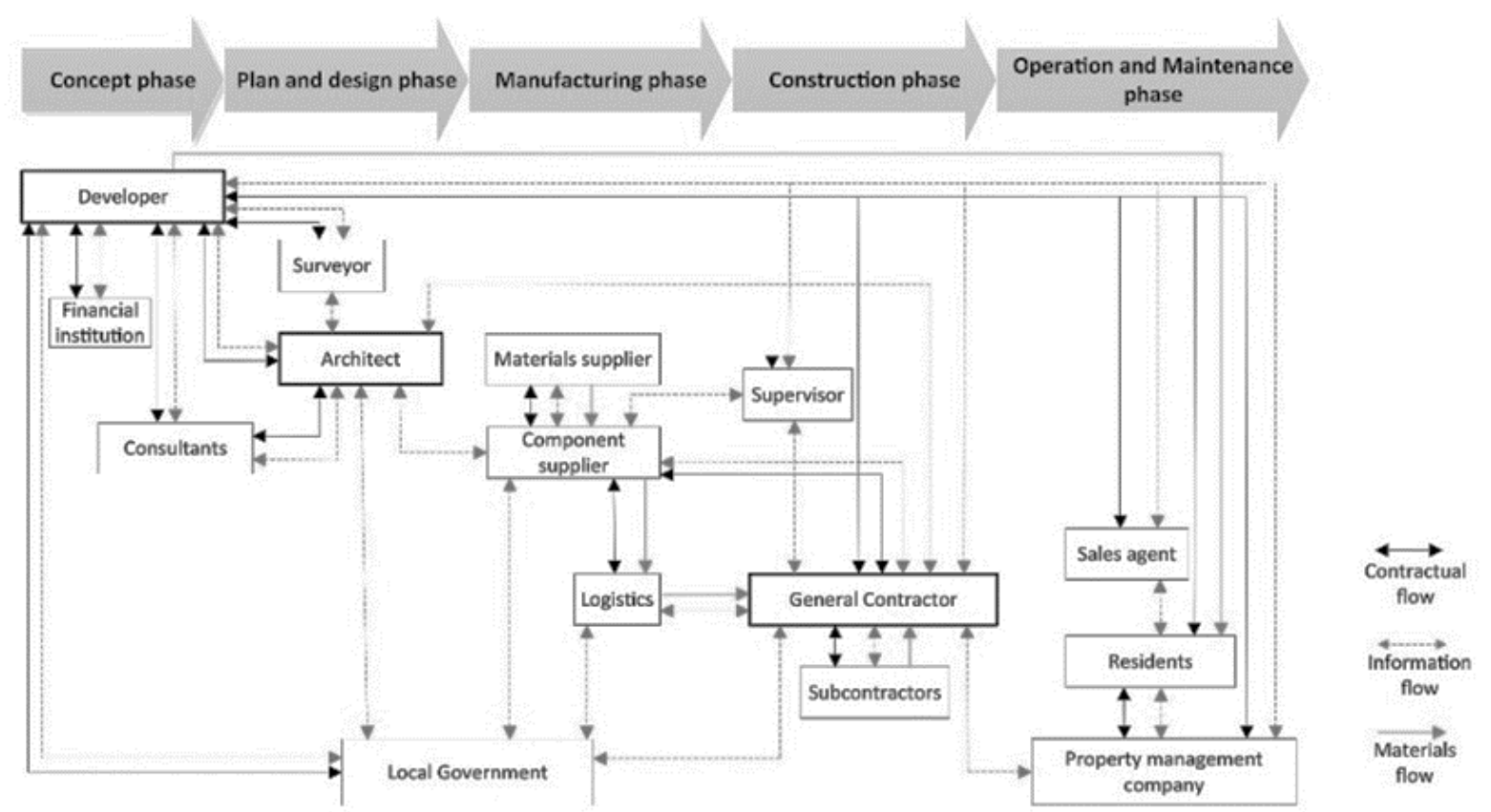

Gambar 1: DBB (Design-Bid-Build) Supply Chain of Housing Project

Sumber: Hongjuan et al, 2019

Tahapan rantai pasok penyediaan perumahan oleh DIRJEN PKP PUPR dibagi menjadi dua kelompok, yaitu supply side dan demand side (Dirjen Pembiayaan PKP, 2017). Kelompok supply side terdiri dari tanah matang, perizinan, bahan bangunan, pembangunan perumahan, sedangkan kelompok demand side terdiri dari pembiayaan primer, penghunian, dan pembiayaan sekunder perumahan (Dirjen Pembiayaan PKP, 2017) seperti yang digambarkan pada gambar berikut ini: 


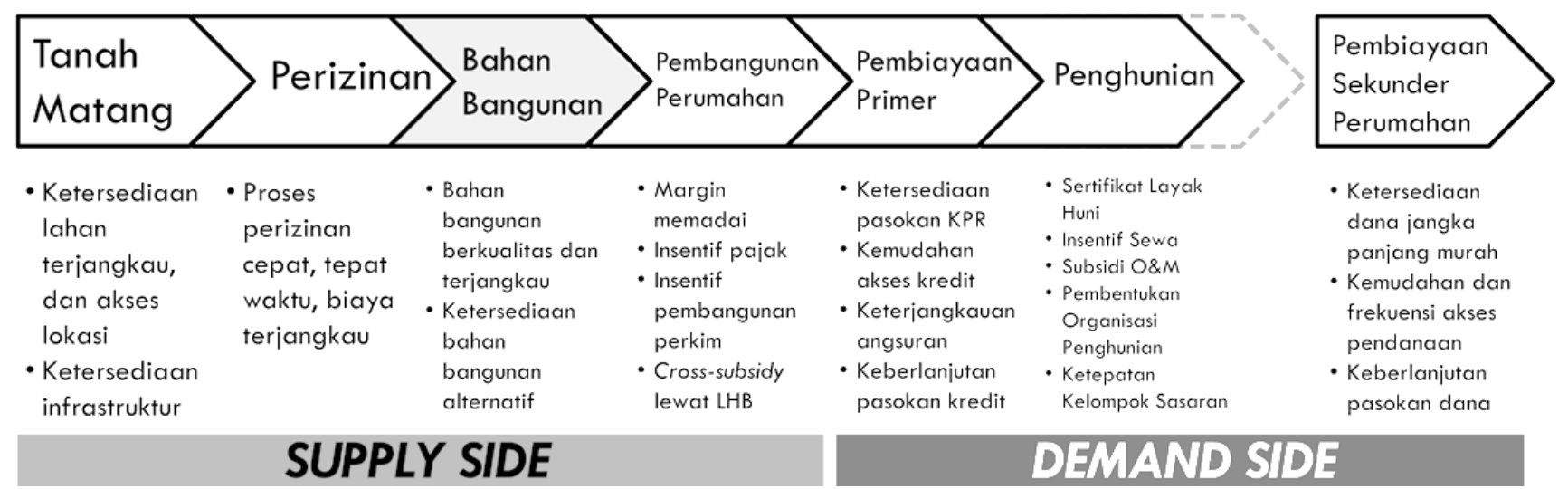

Gambar 2: Rantai Pasok Penyediaan Perumahan di Indonesia

Sumber: Dirjen Pembiayaan PKP, 2017

\section{METODE PENELITIAN}

Penelitian ini menggunakan pendekatan kualitatif. Jenis metode penelitian yang akan digunakan pada pendekatan kualitatif adalah studi kasus (case study). Jenis teknik studi kasus yang akan digunakan pada penelitian ini adalah collective case study, dengan mengangkat Samesta Sentraland Cengkareng dan Apartemen Green Pramuka City untuk menjadi objek studi proses rantai pasok rumah susun yang terjangkau dengan baik dan benar. Data diperoleh melalui wawancara in-depth terhadap pengembang rumah susun yang banyak terlibat dalam proses rantai pasok dari hulu ke hilir seperti perwakilan Samesta Sentraland Cengkareng diperoleh dari bagian legal dan bagian produksi, sedangkan perwakilan Apartemen Green Pramuka City diperoleh dari project manager MK dan konsultan arsitektur. Data juga dapat diperoleh dari pengolahan data yang telah diperoleh untuk menunjang penelitian tersebut.

Metode analisis penelitian yang akan digunakan pada pendekatan kualitatif adalah metode kronologi dan metode perbandingan (komparasi). Metode kronologi digunakan untuk menganalis suatu isu dan permasalahan yang terdalam dari proses tahapan rantai pasok rumah susun, yaitu penyediaan tanah matang, konsep dan perencanaan desain, perizinan, logistik dan bahan bangunan, konstruksi dan pembangunan, serta operasional dan perawatan. Metode perbandingan akan digunakan untuk membandingkan upaya yang dilakukan pengembang terhadap hambatan dan tantangan kinerja proses rantai pasok pada pengembangan rumah susun di Samesta Sentraland Cengkareng dan Apartemen Green Pramuka City.

\section{HASIL DAN PEMBAHASAN}

\section{Gambaran Umum Provinsi DKI Jakarta}

Secara astronomis Provinsi DKI Jakarta terletak antara $6^{0} 12^{`}$ Lintang Selatan dan $106^{\circ} 48^{`}$ Bujur Timur (BPS DKI, 2020 : 3). Kota Jakarta merupakan dataran rendah dengan ketinggian ratarata +7 meter diatas permukaan laut (BPS DKI, 2020 : 3). Luas wilayah Provinsi DKI Jakarta, berdasarkan SK Gubernur Nomor 171 tahun 2007, adalah berupa daratan seluas $662,33 \mathrm{~km}^{2}$ dan berupa lautan seluas 6.977,5 km² (BPS DKI, 2020 : 3). Secara administrasi, Provinsi DKI Jakarta terbagi menjadi 5 wilayah kota administrasi dan 1 kabupaten administrasi. Peruntukan lahan untuk perumahan menduduki proporsi terbesar, yaitu 48,41 persen dari luas daratan utama DKI Jakarta (Pemprov DKI, 2018 : II-18). Sedangkan luasan untuk peruntukan bangunan industri, perkantoran dan perdagangan hanya mencapai 15,68 persen (Pemprov DKI, 2018 : II18). 


\section{Demografi Provinsi DKI Jakarta}

Pertumbuhan penduduk dapat dipengaruhi oleh kelahiran, kematian, dan migrasi. Jumlah penduduk DKI Jakarta tahun 2019 berdasarkan proyeksi penduduk hasil Sensus Penduduk 2010 sebesar 10.557.810 jiwa, laju pertumbuhan penduduk per tahun sebesar 1.19 persen (BPS DKI, 2020 : 76). Kepadatan penduduk DKI Jakarta tahun 2019 adalah 15.900 jiwa setiap $1 \mathrm{~km}^{2}$ (BPS DKI, 2020 : 76). Pertumbuhan penduduk yang dialami Provinsi DKI Jakarta berimplikasi terhadap meningkatnya pasokan hunian. Selain itu dari total penduduk yang tinggal di Provinsi DKI Jakarta, 47,12\% merupakan hunian milik sendiri, 36,36\% hunian berstatus sewa, dan $15,38 \%$ hunian berstatus bebas sewa, sedangkan sisanya adalah hunian milik orangtua, rumah dinas, dan sebagainya (BPS RI, 2019). Dari persentase di atas menggambarkan bahwa masih ada sebagian rumah tangga Provinsi DKI Jakarta membutuhkan hunian sedangkan lahan untuk hunian di Provinsi DKI Jakarta sangat terbatas. Sehingga hunian vertikal atau rumah susun merupakan solusi menangani masalah kebutuhan hunian di Provinsi DKI Jakarta.

\section{Perkembangan Rusunami di DKI Jakarta}

Pada wilayah Jabodetabek sendiri, pengembangan Rumah Susun Sederhana Milik (Rusunami) telah dilakukan oleh pengembang swasta, BUMN, maupun pemerintah. Menurut Mailiando dan Tresani (2018), Pembangunan rusunami terbanyak adalah di Jabodetabek. Perbandingannya dengan kota-kota lainnya adalah 60,4\% di Jabodetabek, 22,4\% di Pulau Jawa selain Jabodetabek, dan 17,2\% di luar pulau Jawa (Mailiando \& Tresani, 2018 : 437). Dari beberapa riwayat pengembangan rusunami di Jabodetabek, adapun beberapa pengembangan yang telah dilakukan di DKI Jakarta untuk kelas menengah maupun MBR yang dapat dilihat pada peta persebaran maupun daftar tabel berikut ini (Dewi \& Tresani, 2018):

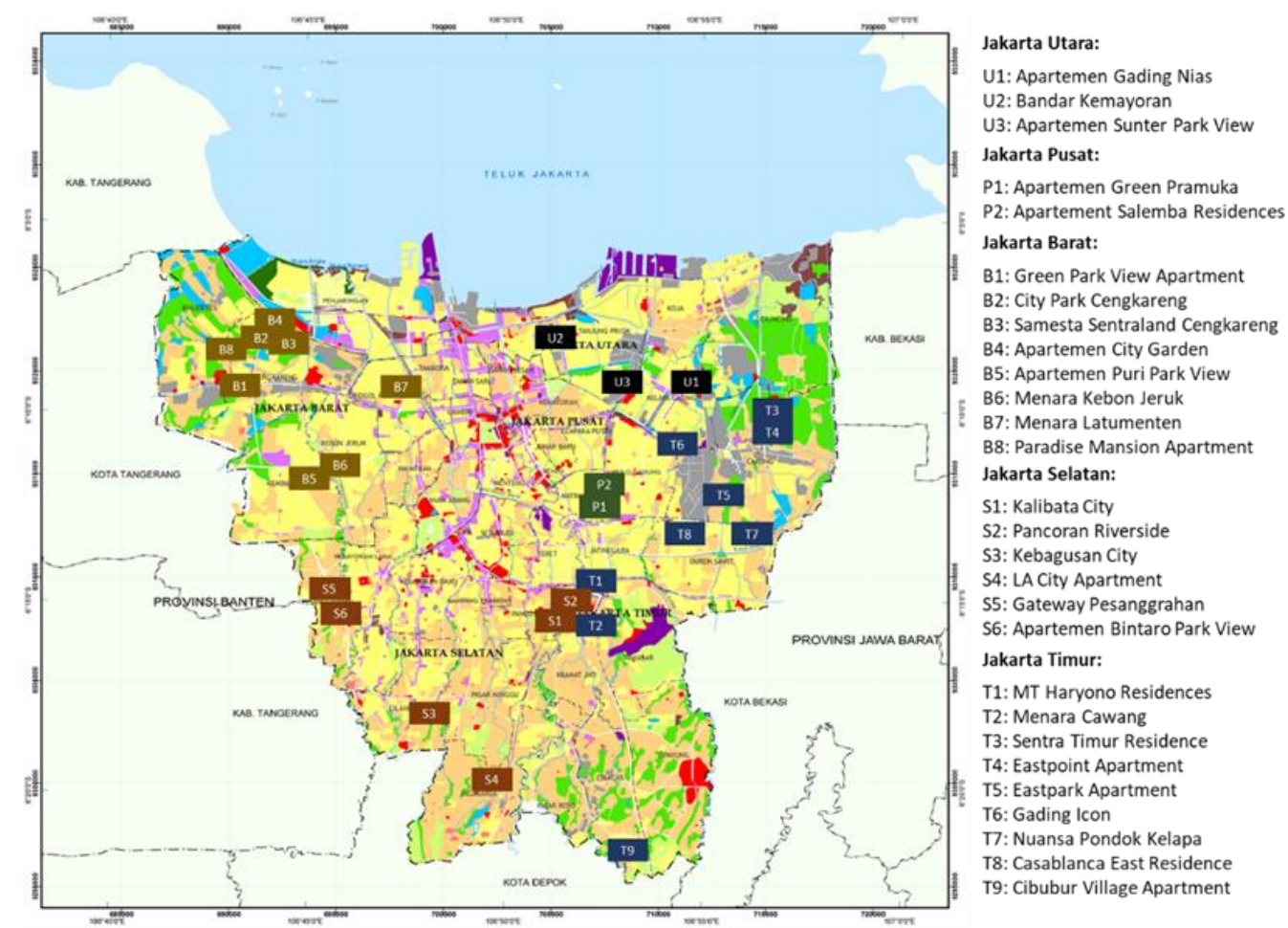

Gambar 3: Peta Persebaran Rusunami di DKI Jakarta Tahun 2007 - 2020

Sumber: (Dewi \& Tresani, 2018) dan Olahan Data Penulis, 2020 


\section{Gambaran Umum Samesta Sentraland Cengkareng}

Samesta Sentraland Cengkareng yang berlokasi di Jl. Boulevard Sentraland Cengkareng, Kelurahan Cengkareng Timur, Kecamatan Cengkareng, Jakarta Barat merupakan pengembangan rumah susun kelas menengah dan MBR. Luas lahan pada pengembangan tersebut adalah 44.980 $\mathrm{m}^{2}$ dengan luasan perencanaannya adalah $41.032 \mathrm{~m}^{2}$ dengan KDB: $43 \%$, KLB: 4 dan KDH $35,08 \%$ (Perumnas, 2020). Proyek ini dikembangkan oleh anak perusahaan Perum Perumnas yaitu PT Samesta Sentraland Cengkareng. Status tanah tersebut adalah tanah HGB diatas HPL, dimana tanah tersebut merupakan salah satu Land Banking dari Perumnas. Samesta Sentraland Cengkareng direncanakan memiliki 5 tower terdiri dari Bunaken, Wakatobi, Samosir, Derawan dan Raja Ampat). Pada saat ini yang sudah terbangun adalah Tower Bunaken, terdiri dari 23 lantai dengan atap (jumlah parkir 3 lantai), serta jumlah unit sebanyak 1.130 unit (Perumnas, 2020). Pada pengembangan Samesta Sentraland Cengkareng, peruntukan untuk kelas MBR sebesar 20\%, sedangkan untuk kelas menengah sebesar $80 \%$. Pada pengembangan Samesta Sentraland Cengkareng, proyek tersebut dipimpin oleh Project Manager Madya, dengan dibantu oleh Manager Keuangan, Manager Pemasaran, dan Manager Konstruksi, dan masing-masing manager juga terdapat staff yang membantu mereka.

\section{Analisis Kronologis Proses Rantai Pasok Samesta Sentraland Cengkareng}

Analisis terhadap proses rantai pasok penyediaan rumah susun yang terjangkau di Samesta Sentraland Cengkareng bertujuan untuk mengetahui indikator proses pekerjaan yang berpengaruh terhadap sisi pasokan dari pengembang beserta stakeholder pada proyek Samesta Sentraland Cengkareng, sesuai dengan indikator tinjauan pustaka yang ada. Adapun indikator utama dari proses rantai pasok penyediaan rumah susun yang ada pada penelitian ini seperti pada tabel berikut ini:

Tabel 1: Analisis Kronologis pada Proses Rantai Pasok Penyediaan Rumah Susun yang Terjangkau di Pengembangan Samesta Sentraland Cengkareng

\begin{tabular}{|c|c|c|}
\hline $\begin{array}{c}\text { Indikator } \\
\text { Tinjauan Pustaka }\end{array}$ & $\begin{array}{c}\text { Indikator yang Perlu } \\
\text { Disempurnakan }\end{array}$ & $\begin{array}{c}\text { Indikator yang Sudah } \\
\text { Dilakukan }\end{array}$ \\
\hline 1. Penyediaan Tanah Matang & & \\
\hline $\begin{array}{l}\text { - Pengembang memiliki tanah lewat Land } \\
\text { Banking (Dirjen Pembiayaan PKP, 2017) } \\
\text { - Melakukan pemecahan Sertifikat HGB } \\
\text { Induk (Dirjen Pembiayaan PKP, 2017) } \\
\text { - Melakukan percepatan penerbitan } \\
\text { Sertifikat Individu (Dirjen Pembiayaan } \\
\text { PKP, 2017) } \\
\text { - Tersedianya akses lokasi dan infrastruktur } \\
\text { (Dirjen Pembiayaan PKP, 2017) } \\
\text { - Melakukan survei tanah dengan koleksi } \\
\text { informasi dan analisis (Hongjuan et al, } \\
\text { 2019) }\end{array}$ & $\begin{array}{l}\text { - Status tanah pada proyek tersebut } \\
\text { masih merupakah tanah HPL, } \\
\text { sehingga masih perlu ditinjau } \\
\text { terlebih lanjut kedepann } \\
\text { pengembangannya } \\
\text { - Penerbitan sertifikat individu juga } \\
\text { perlu diperhatikan cepat } \\
\text { lambatnya penerbitan sesuai } \\
\text { dengan jadwal yang telah } \\
\text { ditentukan } \\
\text { - Akses lokasi pada pengembangan } \\
\text { sudah sangat mendukung, namun } \\
\text { infrastruktur pada lokasi lahan } \\
\text { masih kurang mendukung, } \\
\text { sehingga perlu diperhatikan lebih } \\
\text { matang lagi untuk pengembangan } \\
\text { berikutnya }\end{array}$ & $\begin{array}{l}\text {-Pengembang memiliki tanah } \\
\text { lewat Land Banking Perumnas } \\
\text { - Akses menuju lokasi dan } \\
\text { transportasi publik pada tapak } \\
\text { mendukung } \\
\text { - Melakukan survei tanah dengan } \\
\text { koleksi informasi dan analisis } \\
\text { oleh pengembang }\end{array}$ \\
\hline \multicolumn{3}{|l|}{ 2. Konsep dan Perencanaan Desain } \\
\hline $\begin{array}{l}\text { - Melakukan penyusunan proposal proyek } \\
\text { atau proyek brief yang meliputi } \\
\text { pemeriksaan keuangan proyek, lokasi } \\
\text { situs, dan keadaan lingkungan (Hongjuan } \\
\text { et al, 2019) }\end{array}$ & - Tidak perlu disempurnakan & $\begin{array}{l}\text {-Penyusunan proposal dan studi } \\
\text { kelayakan pada proyek sudah } \\
\text { dilakukan oleh pengembang } \\
\text { untuk menyusun rencana } \\
\text { kelayakan pengembangan pada }\end{array}$ \\
\hline
\end{tabular}


- Melakukan studi kelayakan dengan meminta, meninjau, dan memilih perusahaan untuk mengerjakan suplemen, desain, manufaktur, konstruksi, dll (Hongjuan et al, 2019)

- Melakukan perancangan arsitektural serta detail perancangan, usulan solusi, memerlukan perencanaan dan rekayasa pra-proyek yang lebih intensif (Hongjuan et al, 2019)

- Menyediakan konsultan profesional seperti struktur, lansekap, peralatan arsitektur, dll (Hongjuan et al, 2019)

- Membentuk organisasi proyek, seperti organisasi manajemen proyek, termasuk merekrut pekerja baru, menetapkan institusi baru, dan kantor baru (Hongjuan et al, 2019)

\section{Perizinan}

- Proses perizinan cepat dengan memberikan kemudahan atau keringanan penerbitan IMB oleh pihak pemerintah (Dirjen Pembiayaan PKP, 2017)

- Izin dilakukan tepat waktu dengan efisiensi perizinan dan biaya terjangkau (Dirjen Pembiayaan PKP, 2017)

- Mendapatkan izin perencanaan tata guna lahan konstruksi dan sertifikat hak guna lahan (Hongjuan et al, 2019)

- Memperoleh persetujuan perencanaan proyek konstruksi dan rencana desain dari departemen perencanaan kota yang bertanggung jawab (Hongjuan et al, 2019)

4. Logistik dan Bahan Bangunan

- Menyediakan bahan bangunan yang berkualitas dan terjangkau dengan fabrikasi bahan bangunan lokal terjangkau (Dirjen Pembiayaan PKP, 2017)

- Menyediakan bahan bangunan alternatif dengan pengembangan penggunaan bahan bangunan alternatif (Dirjen Pembiayaan PKP, 2017)

- Melakukan pengaturan transportasi dan risiko pengiriman lebih awal atau penundaan (Hongjuan et al, 2019) proyek

- Konsultan perencana melalui konsultan arsitektural melakukan perancangan arsitektural berdasarkan arahan dari pengembang sesuai dengan peraturan yang berlaku

- Pengembang menyediakan konsultan professional pada tahap perencanaan selain konsultan arsitektural, seperti konsultan ME dan konsultan struktur

- Pembentukan struktur organisasi dan penyediaan konsultan perencana juga sudah dilakukan oleh pengembang pada tahap tersebut
- Proses pemberian izin pada pengembangan seharusnya dilakukan dengan cepat dan tanpa mengalami kesulitan apabila perubahan desain tidak terjadi dan mengalami revisi IMB sesuai dengan jadwal yang telah direncanakan

- Perancangan perlu dimatangkan pada tahap konsep dan perencanaan desain sebelum memasukin tahap perizinan

\section{-Perizinan terhadap pengembangan menyediakan rusunami MBR yang ada pada proyek tersebut berdasarkan syarat izin bangun yang telah ditentukan oleh pemerintah \\ - Pengembangan telah mendapat persetujuan izin dari pihak-pihak instansi pemerintah melalui PTSP}

5. Konstruksi dan Pembangunan

- Tersedianya pembiayaan Kredit

Konstruksi seperti Cross-subsidy lewat

LHB (Dirjen Pembiayaan PKP, 2017)

- Memperhatikan proses tahapan konstruksi seperti material, tenaga kerja dan peralatan (Cox \& Ireland, 2001)〉

- Melakukan pantauan konstruksi, termasuk pengawasan keamanan, pengendalian waktu, dan kualitas pengawasan (Dirjen Pembiayaan PKP, 2017)

- Melibatkan konsultan pelaksana dalam
-Tidak perlu disempurnakan

\begin{tabular}{l} 
- Bahan bangunan yang disediakan \\
juga sudah menggunakan produk \\
lokal walaupun tidak $100 \%$ \\
- Logistik dan bahan bangunan \\
disediakan oleh kontraktor utama \\
berdasarkan RKS yang telah \\
disusun oleh MK \\
- Pengembang juga dapat bekerja \\
sama dengan beberapa supplier \\
bahan bangunan agar dapat \\
memperoleh harga yang \\
terjangkau \\
•Pengembang pada pengerjaan \\
proyeksi juga sudah \\
mengustuskan tim produksi untuk \\
memantau dan memperhatikan \\
proses kontruksi \\
•Pengembang melibatkan \\
konsultan pelaksana (kontraktor \\
dan MK) dalam menjalankan \\
proyek konstruksi \\
•Pengadaan subkontraktor \\
disediakan oleh kontraktor utama \\
\hline
\end{tabular}

- Walaupun pada pengembangan tersebut tidak terdapat crosssubsidy lewat LHB (Lingkungan Hunian Berimbang), namun subsidi silang untuk rusunami MBR dapat diperoleh dari apartemen milik kelas menengah; Pengembangan proyek ini hanya melakukan pinjaman konstruksi dengan Bank BTN

- Perubahan desain seharusnya 
pengerjaan konstruksi (Deshmukh P. S, 2014)

- Melakukan antisipasi perubahan desain dan solusi sengketa (Hongjuan et al, 2019)

- Pengadaan subkontraktor dalam atur penawaran, persiapan panggilan, penilaian subkontraktor, penandatanganan kontrak dengan subkontraktor (Hongjuan et al, 2019)

6. Operasional dan Perawatan

- Melakukan persiapan kontrak, negosiasi dan penandatanganan kepada building maintenance (Hongjuan et al, 2019)

- Mengevaluasi design guidelines, bahan bangunan, detail dan bahan bangunan (HDB, 2010) dapat dihindari pada tahap konstruksi, sehingga tidak mengalami perubahan izin IMB, mesti diselesaikan pada tahapan konsep dan Perencanaan Desain
- Tidak perlu disempurnakan

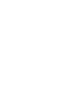

\author{
- Pada proyek ini setelah P3RS \\ terbentuk, maka penghuni juga \\ berhak menentukan property \\ management pilihan mereka; \\ Pada saat proyek baru selesai, \\ pengembang akan membentuk \\ property management sendiri \\ untuk pengelolaan gedung \\ - Pada saat proyek sudah selesai, \\ pengembang melakukan evaluasi \\ terhadap design guidelines \\ - Evaluasi terhadap bahan \\ bangunan serta detail dan metode \\ dilakukan oleh pengembang
}

Sumber: Hasil Wawancara dan Olahan Penulis, 2020

\section{Gambaran Umum Green Pramuka City}

Apartemen Green Pramuka City yang berlokasi di Jl. Jend A Yani Kav. 49, Kelurahan Rawasari, Kecamatan Cempaka Putih, Jakarta Pusat merupakan pengembangan rumah susun kelas menengah. Menurut Project Manager Green Pramuka City (2020), luas lahan pada pengembangan tersebut adalah $129.000 \mathrm{~m}^{2}$ dengan area perencanaan sejumlah 17 Tower dengan 9 Tower sudah terbangun. Proyek ini dikembangkan oleh PT. Duta Paramindo Sejahtera, dengan kerja sama PT Angkasa Pura 1 (Persero) sebagai pemilik tanah. Status tanah tersebut adalah tanah HGB diatas HPL, dengan masa kontrak 30 tahun dan setelahnya dapat diperpanjang hingga 20 tahun. Apartemen Green Pramuka City sudah mendirikan 9 Tower yang terdiri dari Bougenville, Chrysant, Faggio, Nerine, Orchid, Penelope, Pino, Scarlet dan Magnolia. Masingmasing tower terdiri dari 25 lantai, serta jumlah unit keseluruhan pengembangan sebanyak 12.786 unit (yang sudah terbangun 8.700 unit). Pada pengembangan ini tidak terdapat rusunami MBR, sehingga 100\% peruntukannya untuk hunian kelas menengah. Pada pengembangan Green Pramuka City, proyek tersebut dipimpin oleh Project Manager mewakili pengembang, dengan dibantu oleh Arsitektur Studio, Site Manager Arsitektur, Site Manager ME, Site Manager Struktur, Quality Control, dan masing-masing manager juga terdapat staff yang membantu mereka untuk mengawasi pekerjaan kontraktor.

\section{Analisis Kronologis Proses Rantai Pasok Green Pramuka City}

Analisis terhadap proses rantai pasok penyediaan rumah susun yang terjangkau di Apartemen Green Pramuka City bertujuan untuk mengetahui indikator proses pekerjaan yang berpengaruh terhadap sisi pasokan dari pengembang beserta stakeholder pada proyek Apartemen Green Pramuka City, sesuai dengan indikator tinjauan pustaka yang ada. Adapun indikator utama dari proses rantai pasok penyediaan rumah susun yang ada pada penelitian ini seperti pada tabel berikut ini: 
Tabel 2: Analisis Kronologis pada Proses Rantai Pasok Penyediaan Rumah Susun yang Terjangkau di Pengembangan Apartemen Green Pramuka City

\begin{tabular}{|c|c|c|}
\hline $\begin{array}{c}\text { Indikator } \\
\text { Tinjauan Pustaka }\end{array}$ & $\begin{array}{c}\text { Indikator yang Perlu } \\
\text { Disempurnakan }\end{array}$ & $\begin{array}{c}\text { Indikator yang Sudah } \\
\text { Dilakukan }\end{array}$ \\
\hline 1. Penyediaan Tanah Matang & & \\
\hline $\begin{array}{l}\text { - Pengembang memiliki tanah lewat Land } \\
\text { Banking (Dirjen Pembiayaan PKP, 2017) } \\
\text { - Melakukan pemecahan Sertifikat HGB } \\
\text { Induk (Dirjen Pembiayaan PKP, 2017) } \\
\text { - Melakukan percepatan penerbitan } \\
\text { Sertifikat Individu (Dirjen Pembiayaan } \\
\text { PKP, 2017) } \\
\text { - Tersedianya akses lokasi dan infrastruktur } \\
\text { (Dirjen Pembiayaan PKP, 2017) } \\
\text { - Melakukan survei tanah dengan koleksi } \\
\text { informasi dan analisis (Hongjuan et al, } \\
\text { 2019) }\end{array}$ & $\begin{array}{l}\text {-Pengembang tidak memiliki land } \\
\text { banking untuk pengembangan } \\
\text { proyek tersebut, status kerja sama } \\
\text { pada pengembangan ini hanya } \\
\text { sebatas pemilik lahan dengan } \\
\text { pengembang } \\
\text { - Status tanah pada proyek tersebut } \\
\text { masih merupakah tanah HPL, } \\
\text { sehingga masih perlu ditinjau } \\
\text { terlebih lanjut kedepan } \\
\text { pengembangannya } \\
\text {-Penerbitan sertifikat individu juga } \\
\text { perlu diperhatikan cepat } \\
\text { lambatnya penerbitan sesuai } \\
\text { dengan jadwal yang telah } \\
\text { ditentukan walaupun masih } \\
\text { dalam tahap proses }\end{array}$ & $\begin{array}{l}\text {-Pengembang sudah melakukan } \\
\text { pemecahan sertifikat pada } \\
\text { pengembangan tersebut } \\
\text { - Akses lokasi yang strategis } \\
\text { dengan jaringan infrastuktur dan } \\
\text { sarana transportasi yang } \\
\text { mendukung } \\
\text {-Pengembang melakukakan survei } \\
\text { tanah dengan koleksi informasi } \\
\text { dan analisis dengan konsultan } \\
\text { tanah }\end{array}$ \\
\hline \multicolumn{3}{|l|}{ 2. Konsep dan Perencanaan Desain } \\
\hline $\begin{array}{l}\text { - Melakukan penyusunan proposal proyek } \\
\text { atau proyek brief yang meliputi } \\
\text { pemeriksaan keuangan proyek, lokasi } \\
\text { situs, dan keadaan lingkungan (Hongjuan } \\
\text { et al, 2019) } \\
\text { - Melakukan studi kelayakan dengan } \\
\text { meminta, meninjau, dan memilih } \\
\text { perusahaan untuk mengerjakan suplemen, } \\
\text { desain, manufaktur, konstruksi, dll } \\
\text { (Hongjuan et al, 2019) } \\
\text { - Melakukan perancangan arsitektural serta } \\
\text { detail perancangan, usulan solusi, } \\
\text { memerlukan perencanaan dan rekayasa } \\
\text { pra-proyek yang lebih intensif (Hongjuan } \\
\text { et al, 2019) } \\
\text { - Menyediakan konsultan profesional seperti }\end{array}$ & $\begin{array}{l}\text {-Perencanaan sebelum memasukin } \\
\text { tahap desain yang dilakukan oleh } \\
\text { konsultan Arsitektur perlu } \\
\text { disempurnakan lagi } \\
\text { pengembangan kedepannya, } \\
\text { sebaiknya proposal dan studi } \\
\text { kelayakan proyek perlu disusun } \\
\text { agar pada saat penentuan konsep } \\
\text { dan desain oleh para konsultan } \\
\text { lebih terarah }\end{array}$ & $\begin{array}{l}\text {-Pengembang bekerja sama } \\
\text { dengan konsultan arsitektur } \\
\text { dalam menentukan rencana dan } \\
\text { rancangan proyek sesuai dengan } \\
\text { peraturan lokasi yang telah } \\
\text { ditentukan oleh pemerintah } \\
\text { beserta perizinan } \\
\text {-Pengembang menyediakan } \\
\text { konsultan perencana selain } \\
\text { konsultan arsitektur, seperti } \\
\text { konsultan struktur dan konsultan } \\
\text { ME pada pengembangan tersebut } \\
\text {-Pengembang membentuk struktur } \\
\text { organisasi, terutama tim } M K-I n \\
\text { House sebagai pelaksana } \\
\text { pengerjaan proyek }\end{array}$ \\
\hline
\end{tabular}
struktur, lansekap, peralatan arsitektur, dll (Hongjuan et al, 2019)

- Membentuk organisasi proyek, seperti organisasi manajemen proyek, termasuk merekrut pekerja baru, menetapkan institusi baru, dan kantor baru (Hongjuan et al, 2019)

\begin{tabular}{|c|c|c|}
\hline 3. Perizinan & & \\
\hline $\begin{array}{l}\text { - Proses perizinan cepat dengan } \\
\text { memberikan kemudahan atau keringanan } \\
\text { penerbitan IMB oleh pihak pemerintah } \\
\text { (Dirjen Pembiayaan PKP, 2017) } \\
\text { - Izin dilakukan tepat waktu dengan } \\
\text { efisiensi perizinan dan biaya terjangkau } \\
\text { (Dirjen Pembiayaan PKP, 2017) } \\
\text { - Mendapatkan izin perencanaan tata guna } \\
\text { lahan konstruksi dan sertifikat hak guna } \\
\text { lahan (Hongjuan et al, 2019) } \\
\text { - Memperoleh persetujuan perencanaan }\end{array}$ & $\begin{array}{l}\text { - Mempertegas peraturan } \\
\text { pemerintah dalam memberi izin } \\
\text { mendirikan bangunan untuk } \\
\text { apartemen kelas menengah perlu } \\
\text { mempertimbangkan penyediaan } \\
\text { hunian untuk rusunami MBR } \\
\text {-Pemerintah juga dapat turut } \\
\text { membantu pengembang dalam } \\
\text { proses kemudahan pemberian } \\
\text { izin kepada pengembang yang } \\
\text { ingin mendirikan rusunami }\end{array}$ & $\begin{array}{l}\text {-Proses perizinan cepat dengan } \\
\text { memberikan kemudahan atau } \\
\text { keringanan penerbitan IMB oleh } \\
\text { pihak pemerintah melalui PTSP } \\
\text { (untuk pengembangan baru); Izin } \\
\text { dilakukan tepat waktu dan efisien } \\
\text { (berdasarkan jadwal yang } \\
\text { ditentukan oleh PTSP) } \\
\text {-Pengembangan telah mendapat } \\
\text { persetujuan izin dari pihak-pihak } \\
\text { instansi pemerintah melalui PTSP }\end{array}$ \\
\hline
\end{tabular}


proyek konstruksi dan rencana desain dari departemen perencanaan kota yang bertanggung jawab (Hongjuan et al, 2019)

melalui kerja sama dengan

BUMN atau BUMD dalam

menjalankan visi-misi pemerintah

- Apabila dalam waktu yang akan

datang pengembang masih

terdapat beberapa

pengembangan, pengembang

perlu mempertimbangkan

pengajuan izin IMB beberapa

tower secara bersamaan agar

perizinan dapat dilakukan secara

efisien

4. Logistik dan Bahan Bangunan

- Menyediakan bahan bangunan yang berkualitas dan terjangkau dengan fabrikasi bahan bangunan lokal terjangkau (Dirjen Pembiayaan PKP, 2017)

- Menyediakan bahan bangunan alternatif dengan pengembangan penggunaan bahan bangunan alternatif (Dirjen Pembiayaan PKP, 2017)

- Melakukan pengaturan transportasi dan risiko pengiriman lebih awal atau penundaan (Hongjuan et al, 2019)
-Salah satu hal yang menjadi kesulitan untuk pengembang menyediakan rusunami MBR adalah pemilihan bahan bangunan yang berkualitas tinggi oleh calon pembeli

- Pengembang juga dapat bekerja sama dengan beberapa supplier bahan bangunan agar dapat memperoleh harga yang terjangkau

-Sebagian besar pengembangan proyek menggunakan bahan bangunan lokal

- Logistik dan bahan bangunan disediakan oleh kontraktor utama berdasarkan RKS yang telah disusun oleh MK

-Pengembang melakukan pengaturan transportasi dan risiko pengiriman lebih awal atau penundaan melalui kontraktor utama

5. Konstruksi dan Pembangunan Konstruksi seperti Cross-subsidy lewat LHB (Dirjen Pembiayaan PKP, 2017)

- Memperhatikan proses tahapan konstruksi seperti material, tenaga kerja dan peralatan

- Melakukan pantauan konstruksi, termasuk pengawasan keamanan, pengendalian waktu, dan kualitas pengawasan (Dirjen Pembiayaan PKP, 2017)

- Melibatkan konsultan pelaksana dalam pengerjaan konstruksi (Deshmukh P. S, 2014)

- Melakukan antisipasi perubahan desain dan solusi sengketa (Hongjuan et al, 2019)

- Pengadaan subkontraktor dalam atur penawaran, persiapan panggilan, penilaian subkontraktor, penandatanganan kontrak 2019)
- Tersedianya pembiayaan Kredit dengan subkontraktor (Hongjuan et al,
- Pada proyek ini pengembang tidak menyediakan pembiayaan kredit konstruksi seperti crosssubsidy lewat LHB, karena sepenuhnya proyek ini tidak terdapat penyediaan rusunami MBR; Pengembangan proyek ini hanya melakukan pinjaman konstruksi dengan Bank BTN
-Pengembang melalui $M K$-In House memperhatikan proses tahapan konstruksi seperti material, tenaga kerja dan peralatan, melakukan pantauan konstruksi (termasuk pengawasan keamanan, pengendalian waktu, dan kualitas pengawasan)

-Pengembang melibatkan konsultan pelaksana dalam pengerjaan konstruksi, dan pengadaan subkontraktor dalam atur penawaran, persiapan panggilan, penilaian subkontraktor, penandatanganan kontrak dengan subkontraktor dikoordinasi oleh konsultan pelaksana (kontraktor utama)

- Melakukan antisipasi perubahan desain dan solusi sengketa dengan menetapkan konsep desain yang telah dilakukan agar tidak mengalami perubahan desain pada saat memasuki tahap konstruksi

\begin{tabular}{lc}
\hline 6. Operasional dan Perawatan & \\
\hline - Melakukan persiapan kontrak, negosiasi & $\bullet$ Tidak perlu disempurnakan \\
dan penandatanganan kepada building & $\bullet$ Pada proyek ini setelah P3RS \\
maintenance (Hongjuan et al, 2019) & terbentuk, maka penghuni juga \\
- Mengevaluasi design guidelines, bahan & berhak menentukan property \\
bangunan, detail dan bahan bangunan & management pilihan mereka; \\
$($ HDB, 2010) & Pada saat proyek baru selesai, \\
\hline
\end{tabular}




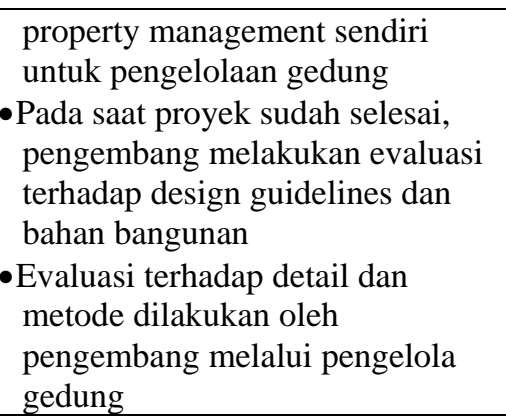

Sumber: Hasil Wawancara dan Olahan Penulis, 2020

\section{Analisis Komparasi Upaya Pengembang BUMN dan Swasta Dalam Mengatasi Hambatan dan Tantangan pada Proses Rantai Pasok}

Analisis perbandingan upaya pengembang BUMN dan swasta dalam mengatasi hambatan dan tantangan pada proses rantai pasok penyediaan rumah susun yang terjangkau di DKI Jakarta dapat diilustrasikan seperti pada tabel berikut ini:

Tabel 3: Analisis Perbandingan Upaya Pengembang BUMN dan Swasta Dalam Mengatasi Hambatan dan Tantangan pada Proses Rantai Pasok Penyediaan Rumah Susun yang Terjangkau di DKI Jakarta

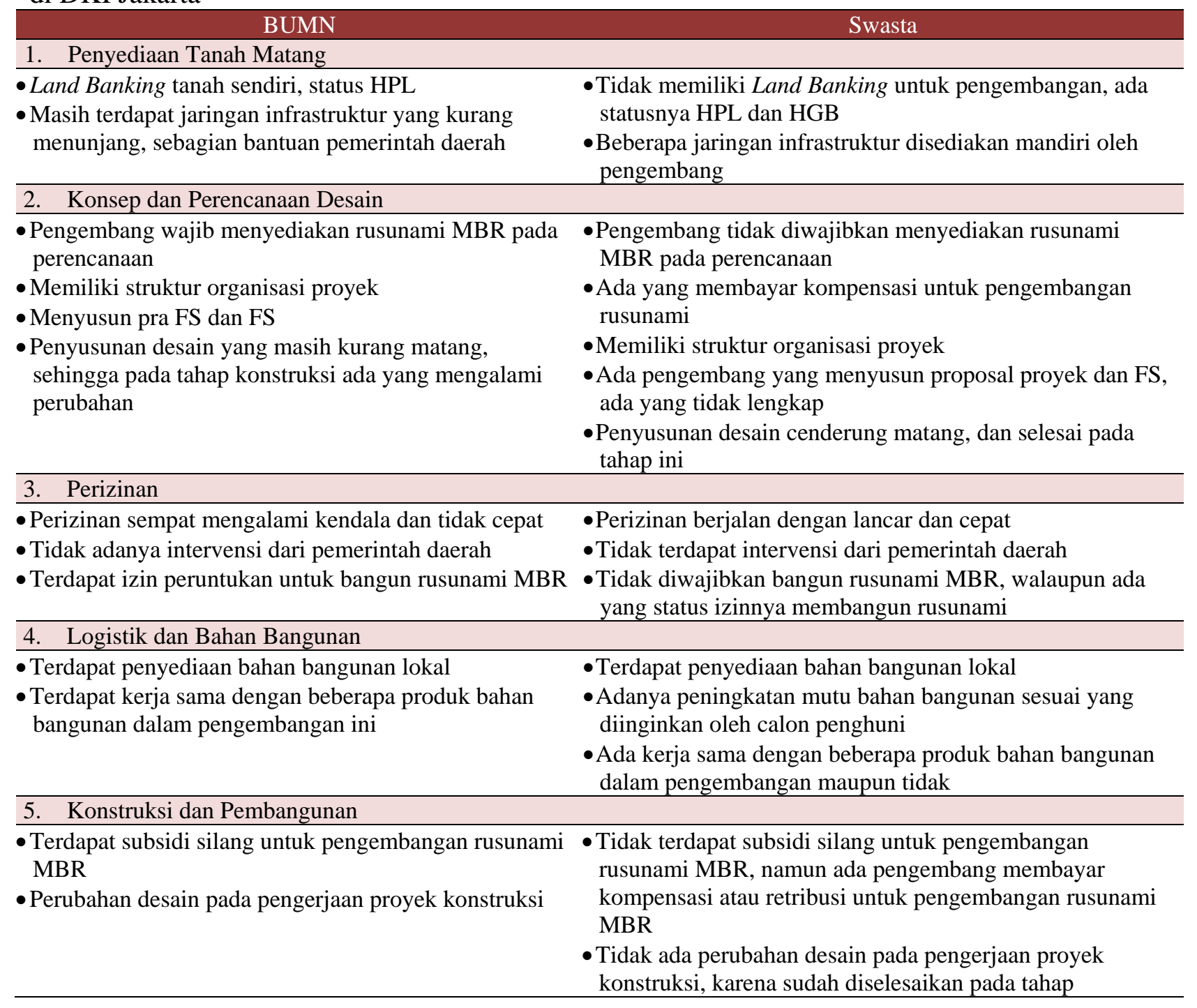




\section{Operasional dan Perawatan}

- Review desain sudah dilakukan sebelum memasuki tahap operasional dan perawatan

- Pengembang sudah membentuk property management

- Evaluasi desain, bahan bangunan, detail dan metode sudah dilakukan perencanaan

- Pengembang sudah membentuk property management

-Evaluasi desain, bahan bangunan, detail dan metode sudah dilakukan

Sumber: Hasil Wawancara dan Olahan Penulis, 2020

Adapun usulan skema proses rantai pasok pada rumah susun yang terjangkau oleh penulis berdasarkan hasil analisis yang sudah dilakukan yaitu seperti pada ilustrasi pada gambar berikut ini:

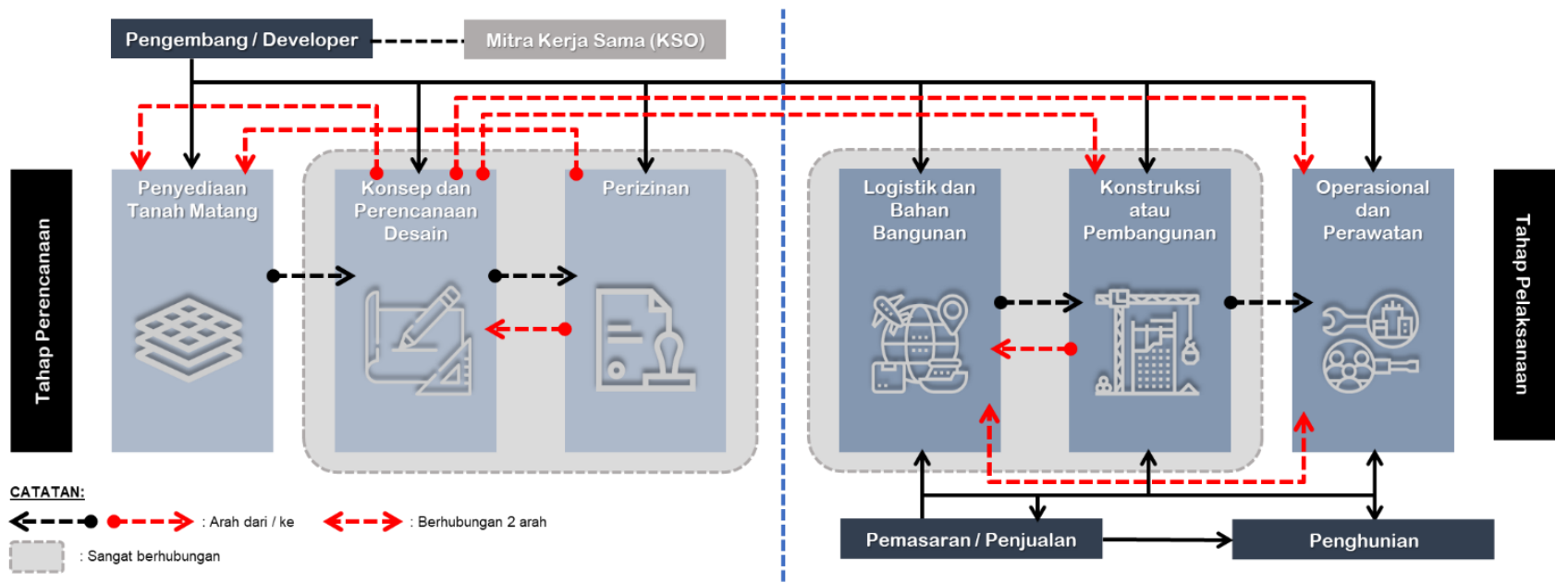

Gambar 4: Alur Proses Rantai Pasok Pengembangan Rumah Susun yang Terjangkau oleh Penulis Sumber: Olahan Penulis (2020)

\section{KESIMPULAN DAN SARAN}

Berdasarkan hasil analisis kronologis dan komparasi diatas, dapat disimpulkan bahwa penyediaan rusunami masih sangat erat hubungannya dengan proses rantai pasok. Pada tahap penyediaan tanah matang, pengembang BUMN memiliki Land Banking untuk pendirian rumah susun yang terjangkau, sedangkan pengembang swasta tidak ada. Pada tahap konsep dan perencanaan desain, masing-masing pengembang terdapat permasalahan mereka masing-masing, namun berjalan dengan lancar. Pada tahap perizinan, intervensi pemerintah terhadap pengembangan rusunami MBR di BUMN dan Swasta kurang kuat. Pada tahap penyediaan bahan bangunan dan logistik, semua pengembang sebagian besar menggunakan bahan bangunan lokal, pengembang BUMN dan swasta mengadakan kerja sama dengan beberapa produk pada pengembangan. Pada tahap konstruksi dan pembangunan, Pengembang BUMN sempat mengalami perubahan desain, sedangkan pengembang Swasta tidak mengalami hal tersebut. Pada tahap operasional dan perawatan, semua pengembang telah melakukan pembentukan property management dan evaluasi terhadap pengembangan (desain, bahan bangunan, detail dan metode).

Peran Pemerintah (baik pusat maupun daerah) memiliki peranan penting dalam menjalankan rantai pasok penyediaan rumah susun yang terjangkau, seperti sebagai pemilik land-banking yang dapat melakukan kerja sama dengan pihak lain, dapat membantu seluruh proyek menjadi lebih efisien, penetapan peraturan dalam penyediaan rusunami MBR, perizinan, standardisasi 
perencanaan desain, akses penyediaan bahan bangunan yang terjangkau, dan lain-lain. Peran Pengembang juga memiliki pernanan penting dalam menjalankan rantai pasok penyediaan rumah susun yang terjangkau, seperti bekerja sama dengan pemilik tanah, apabila tidak memiliki tanah, pengembangan Rusunami MBR, membantu pemerintah dalam mewujudkan iklim Lingkungan Hunian Berimbang (LHB), dan lain-lain.

\section{REFERENSI}

BPS DKI. (2020). Provinsi DKI Jakarta Dalam Angka 2020. Jakarta: BPS DKI Jakarta.

BPS RI. (2019). Statistik Kesejahteraan Rakyat 2019. Jakarta: Badan Pusat Statistik.

Deshmukh P. S, M. A. (2014). Supply Chain Management in Residential Construction Sector. International Journal of Engineering and Advanced Technology (IJEAT), 87-90.

Dewi, \& Tresani, N. (2018). Studi Peranan Faktor Lokasi Terhadap Profil Penghuni Rumah Susun Sederhana Milik di Jakarta. Jurnal Muara Sains, Teknologi, Kedokteran, dan Ilmu Kesehatan Vol. 2, No. 1, 144-154.

Dirjen Pembiayaan PKP. (2017). Kebijakan dan Program Pembiayaan Perumahan. Medan: Kementrian PUPR.

Green Pramuka City. (2019). House Rules Edisi 4: Apartemen Green Pramuka City. Jakarta: Green Pramuka City.

Green Pramuka City. (2020). Green Pramuka City: Hunian Praktis di Pusat Jakarta. Jakarta: Green Pramuka City.

Hayyu, A. M. (2020, Agustus 21). Mengelola Urbanisasi untuk Pertumbuhan Ekonomi. From Detik.com: $\quad$ https://news.detik.com/kolom/d-4504255/mengelola-urbanisasi-untukpertumbuhan-ekonomi

HDB. "Our Commitment". diterima dari Housing \& Development Board: https://www.hdb.gov.sg/cs/infoweb/about-us/research-and-innovation/constructionproductivity/our-commitment (5 Desember 2018)

Hongjuan et al. (2019). Exploring Transaction Costs In The Prefabricated Housing Supply Chain. Journal of Cleaner Production 226, 550-563.

Peraturan Pemerintah Republik Indonesia Nomor 14 Tahun 2016 Tentang Penyelenggaraan Perumahan dan Kawasan Permukiman

PUPR, T. P. (2019). Kamus Istilah Perumahan. Jakarta: Kementerian Pekerjaan Umum dan Perumahan Rakyat.

Mailiando, M., \& Tresani, N. (2018). Faktor-Faktor yang Mempengaruhi Keputusan MBR Membeli Rusunami di Kota Bekasi (Studi Kasus: Sentraland \& Vida Bekasi). Jurnal Muara Sains, Teknologi, Kedokteran, dan Ilmu Kesehatan. 2(2). pp 534-547.

Pemprov DKI. (2018). Peraturan Daerah Nomor 1 Tahun 2018 tentang RPJMD Provinsi DKI Jakarta Tahun 2017-2022. Jakarta: Pemerintah Provinsi DKI Jakarta.

Perum Perumnas. (2018). Laporan Tahunan Perumnas 2018: Memberikan Nilai Tambah Melalui Transformasi Berkelanjutan. Jakarta: Perumnas.

Perumnas. (2020). Presentasi Samesta Sentraland Cengkareng. Jakarta: Perumnas.

Roberts, M. (2019). Time to ACT: Realizing Indonesia's Urban Potential. Washington, DC: World Bank Group.

Triatmojo, D. (2020, 02 14). Hunian Jakarta Backlog 10 Persen, Pemprov DKI Akan Dongkrak Perumahan Vertikal Kelas Menengah Bawah. Diterima dari Tribunnews.com: https://www.tribunnews.com/bisnis/2020/02/14/hunian-jakarta-backlog-10-persenpemprov-dki-akan-dongkrak-perumahan-vertikal-kelas-menengah-bawah 
TERJANGKAU OLEH PENGEMBANG BUMN DAN SWASTA DI DKI

JAKARTA (STUDI KASUS: SAMESTA SENTRALAND CENGKARENG

DAN GREEN PRAMUKA CITY) 